\title{
Macromonomer Preparation by Radical Polymerization and Copolymerization of the Unsaturated Tetramer of Methyl Acrylate
}

\author{
Tomoyuki Hirano, Per B. Zetterlund, and Bunichiro YAmadA ${ }^{\dagger}$ \\ Department of Applied and Bioapplied Chemistry, Graduate School of Engineering, Osaka City University, \\ Sugimoto, Sumiyoshi-ku, Osaka 558-8585, Japan
}

(Received December 20, 2002; Accepted March 30, 2003)

\begin{abstract}
The unsaturated tetramer of methyl acrylate $\left(\mathrm{CH}_{2}=\mathrm{CXCH}_{2} \mathrm{CHXCH}_{2} \mathrm{CHXCH}_{2} \mathrm{CH}_{2} \mathrm{X}\right.$, where $\mathrm{X}=\mathrm{CO}_{2} \mathrm{Me}$ : MATe) was homo- and copolymerized by radical means as a polymerizable acrylic ester bearing a bulky $\alpha$-substituent. MATe homopolymerization in bulk yielded low molecular weight polymer consisting of the MATe units and 2-carbomethoxy-2-propenyl $\left(\mathrm{CH}_{2}=\mathrm{C}\left(\mathrm{CO}_{2} \mathrm{Me}\right) \mathrm{CH}_{2}-\right) \omega$-end groups as a result of addition of propagation and simultaneous $\beta$-fragmentation of propagating radicals, expelling $\cdot \mathrm{CHXCH}_{2} \mathrm{CHXCH}_{2} \mathrm{CH}_{2} \mathrm{X}$ which adds to MATe to initiate a new chain. The end groups, introduced almost quantitatively in bulk at $60^{\circ} \mathrm{C}$ or above, were partly consumed by propagating radical addition. Copolymerizations of MATe with cyclohexyl acrylate (CHA) revealed that MATe is as reactive as CHA toward the poly(CHA) radical, and MATe is less reactive than CHA radical toward poly(MATe) radical by a factor of only 1.4. These results suggest that the poly(MATe) bearing the unsaturated end group can be a macromonomer copolymerizable with CHA to yield a highly branched structure because of the similarity in structure with the unsaturated end group of MATe. Comparison of MATe with unsaturated trimer and dimer of methyl acrylate indicated that the more significant steric hindrance of the $\alpha$-substituent of MATe in homo- and copolymerization considerably facilitates introduction of the propenyl end group.

KEY WORDS End Group / Fragmentation / Chain Transfer / Steric Hindrance / Molecular Weight / Monomer Reactivity Ratios /
\end{abstract}

Methyl $\alpha$-ethylacrylate homopolymerizes at an extremely low rate to low molecular weight because the steric hindrance of the $\alpha$-ethyl group significantly suppresses propagation but not termination. ${ }^{1,2}$ However, a variety of $\alpha$-(substituted methyl)acrylic esters readily polymerize despite the presence of larger $\alpha$-substituents than the ethyl group. The polymerizabilities of the $\alpha$-(substituted methyl)acrylates are accounted for by the favorable balance of slow propagation and slow termination arising from the steric hindrance., Some $\alpha$-(substituted methyl)acrylates such $\alpha$-(bromomethyl)-,$^{5-7} \quad \alpha$-(akylsulfenylmethyl)- ${ }^{8-10}$ and $\alpha$ (arylslufonylmethyl)acrylates ${ }^{11}$ do not homopolymerize nor copolymerize with common monomers because of fast addition fragmentation chain transfer (AFCT). The radicals formed by addition of propagating radicals from common monomers to these acrylates readily undergo fragmentation to introduce the 2-carbalkoxy-2-propenyl $\left(\mathrm{CH}_{2}=\mathrm{C}\left(\mathrm{CO}_{2} \mathrm{R}\right) \mathrm{CH}_{2}-\right)$ $\omega$-end group and the corresponding $\alpha$-end groups. Furthermore, methyl $\alpha$-(chloromethyl)acrylate, ${ }^{12}$ methyl $\alpha$-(2-carbomethoxyethyl)acrylate (the dimer of methyl acrylate, MAD) ${ }^{13,14}$ and methyl $\alpha$-(2,4dicarbomethoxybutyl)acrylate (the trimer of methyl acrylate, MAT) $)^{15,16}$ function as polymerizable

${ }^{\dagger}$ To whom correspondence should be addressed. monomers and AFCT agents, simultaneously.

$\alpha$-(Substituted methyl)acrylic esters acting as AFCT agents, e.g., methyl $\alpha$-(bromomethyl)acrylate (MBMA), can introduce the $\omega$-propenyl end group and the $\alpha$-end group (both moieties of the AFCT agent) at the chain ends of poly(acrylic ester), poly(styrene), and poly(methyl methacrylate)., ${ }^{5,17}$ The same unsaturated end group is formed by disproportionation of poly(methyl methacrylate) radicals. ${ }^{18}$ However, the unsaturated end group bound to high molecular weight poly(methyl methacrylate) has never drawn much attention as a reactive functional group for further reaction. Oligomers bearing substituted propenyl end groups can be prepared by catalytic chain transfer polymerization (CCTP) of $\alpha$-methylvinyl monomers such as methyl methacrylate and $\alpha$-methylstyrene using cobalt catalysts. ${ }^{19,20}$ Polymer or oligomer formed by CCTP has the propenyl end group bound to a quaternary carbon, and radical addition to the unsaturated end group tends to result in cleavage of the bond between the end group and the quaternary carbon to generate the propagating radical of the $\alpha$-methylvinyl monomer. ${ }^{21,22}$ In order to use this type of polymer as macromonomer, $\beta$-fragmentation of the adduct radical must be suppressed. However, effective suppression of the fragmentation is impractical.

An alternative route to obtain polymer bearing the 
Table I. Homopolymerization of MATe in bulk

\begin{tabular}{|c|c|c|c|c|c|c|}
\hline$\frac{[\mathrm{MATe}]}{\mathrm{mol} \mathrm{L}^{-1}}$ & $\frac{[\mathrm{I}]}{\mathrm{mol} \mathrm{L}^{-1}}$ & $\frac{\text { Temp. }}{{ }^{\circ} \mathrm{C}}$ & $\frac{\text { Time }}{\mathrm{h}}$ & $\frac{\text { Convn. }}{\%}$ & $\begin{array}{c}M_{\mathrm{n}} \\
(\mathrm{GPC})\end{array}$ & $M_{\mathrm{w}} / M_{\mathrm{n}}$ \\
\hline 3.2 & AIBN, 0.05 & 60 & 10 & 2.6 & 2300 & 1.4 \\
\hline 3.2 & $\mathrm{ACN}, 0.05$ & 90 & 6 & 6.7 & 2100 & 1.4 \\
\hline
\end{tabular}

$\omega$-propenyl end group is high temperature polymerizations of acrylic ester and styrene. ${ }^{23,24}$ During the polymerizations, mid-chain radicals formed primarily by backbiting undergo $\beta$-fragmentation resulting in low molecular weight polymer bearing the propenyl end group. ${ }^{25-28}$ In order to attain sufficiently fast $\beta$ fragmentation of the mid-chain radicals the polymerization should be conducted at high temperature. It is noteworthy that the propagating radicals of MAD and MAT are structurally similar to the mid-chain radicals in acrylate polymerization, and the behavior of MAD and MAT and their propagating radicals can be regarded as models of the propenyl end group and the adduct radicals derived, respectively. MAD and MAT, which are unsaturated oligomers of methyl acrylate (MAOL), both undergo homopolymerization resulting in polymers with the unsaturated $\omega$-end group arising from fragmentation of propagating radicals, particularly at $100^{\circ} \mathrm{C}$ or above. ${ }^{13-15}$

Our recent studies ${ }^{14,22}$ have revealed that the propenyl end groups bound to poly(acrylic ester) and poly(styrene) chains are as reactive as acrylic esters and styrene toward the respective polymer radicals to form copolymers. Therefore, AFCT introducing the $\omega$ propenyl end group can be an efficient route to prepare radically copolymerizable macromonomers by radical polymerization. Although MAD mainly functions as monomer forming the polymer main chain at $60^{\circ} \mathrm{C}$ due to the fragmentation reaction not being sufficiently fast, the efficiency of the $\omega$-end group introduction increases with temperature as confirmed by ${ }^{1} \mathrm{H}$ NMR structural analysis and $M_{\mathrm{n}}$ measurement by gel permeation chromatograph (GPC). ${ }^{13}$ Polymerization of MAT, on the other hand, yields macromonomer more efficiently than MAD. ${ }^{15}$ MAOLs such as MAT and MAD, with the same chemical composition as monomeric methyl acrylate (MA), are considered to be more attractive AFCT agents for acrylate polymerization than MBMA, which introduces bromine as the $\alpha$-end group via AFCT. However, the polymerization conditions should be carefully chosen to enhance the fragmentation rate of the MAOL radicals.

This paper describes the polymerization and copolymerization of methyl acrylate tetramer (MATe) as a polymerizable AFCT agent as a means of macromonomer preparation. The reactivities of the se- ries of MAOLs of MAD, MAT, and MATe were estimated based on polymerization and copolymerization data, and compared as models for the propenyl end group.

\section{EXPERIMENTAL}

MATe was synthesized by the Mannich reaction of MAT as previously reported. ${ }^{16,30}$ Cyclohexyl acrylate (CHA) was commercially available and was used after distillation under reduced pressure. 2,2-Azobisisobutyronitrile (AIBN) and 1,1-azobiscyclohexane-1-carbonitrile (ACN) were commercially available. Homopolymerizations (in bulk) and copolymerizations (in benzene) were carried out in Pyrex ampoules sealed under vacuum. After polymerization of MATe, the solvent was evaporated from the polymerization mixture using a rotary evaporator. A preparative high performance liquid chromatography (HPLC) was employed to remove the unreacted MATe from the polymerization mixture, and poly(MATe) obtained was submitted for ${ }^{1} \mathrm{H}$ NMR and GPC analysis. In the case of polymerizations of MAT, the polymer was precipitated by a large amount of hexane. It was confirmed by GPC that no oligomeric products remain in the hexane solution. The monomer conversion was calculated from the weight of the dried polymer.

A Japan Analytical Industry LC-908 equipped with JAIGEL columns using chloroform as eluent. ${ }^{1} \mathrm{H}$ NMR spectra were recorded on a JEOL JNM a-400 spectrometer at $400 \mathrm{MHz}$. Deuteriochloroform and tetramethylsilane were used as solvent and internal standard, respectively. Molecular weights were measured using a Tosoh 8000 series high-performance liquid chromatograph equipped with TSK-gel columns G5000HHR, GMultiporeHXL-M, and GMHHR-L connected in this order, and THF was used as eluent. Molecular weights were calibrated by poly(styrene) standards $\left(M_{\mathrm{n}}=5.0 \times 10^{2} \sim 1.09 \times 10^{6}\right)$.

\section{RESULTS AND DISCUSSION}

\section{Homopolymerization}

MATe polymerized slowly to low $M_{\mathrm{n}}$ as summarized in Table I. The ${ }^{1} \mathrm{H}$ NMR spectrum of poly(MATe), which exhibits resonances due to the propenyl end 
group as shown in Figure 1, is similar to that of poly(MA) with the propenyl end group except for the presence of the more intense resonances due to the methoxy groups. The spectral intensity ratio of the resonances ascribed to the olefinic protons $(5.45-5.80$ and $6.08-6.35 \mathrm{ppm})$ to that of the methoxy protons $(3.45-$ $3.80 \mathrm{ppm}$ ) allowed calculation of the end group content relative to the MATe units incorporated in the main chain. The $k_{\mathrm{p}} / k_{\mathrm{f}}$ values for the polymerization of MATe at 60 and $90^{\circ} \mathrm{C}$ were calculated from eq 1 :
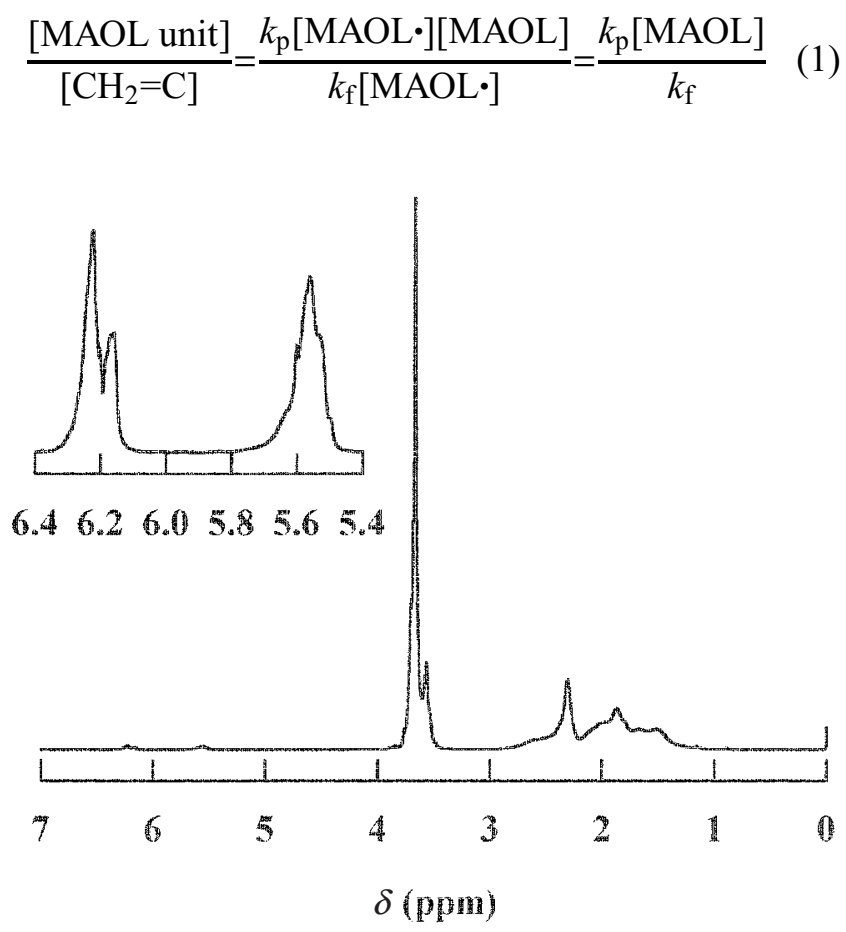

Figure 1. ${ }^{1} \mathrm{H}$ NMR spectrum of the polymer obtained at $60{ }^{\circ} \mathrm{C}$ under the conditions of $[\mathrm{MATe}]=3.2 \mathrm{~mol} \mathrm{~L}^{-1}$, and $[\mathrm{AIBN}]=$ $5.0 \mathrm{mmol} \mathrm{L}^{-1}$. where $k_{\mathrm{p}}$ and $k_{\mathrm{f}}$ denote the rate constants of propagation and fragmentation, respectively (Scheme 1), and [MAOL unit] and $\left[\mathrm{CH}_{2}=\mathrm{C}\right]$ are the contents of MAOL units in the main chain and unsaturated end groups, respectively. Eq 1 is based on the assumption that the unsaturated end groups do not undergo further reactions. The radical expelled by $\beta$-fragmentation, $\mathrm{X} \cdot$, would smoothly add to MAOL to initiate a new chain. If the structure of poly(MAOL) is given by $\mathbf{1}$, i.e., if fragmentation is the main end forming event as opposed to bimolecular termination, then the degree of polymerization is given by $\left([\mathrm{MAOL}\right.$ unit $\left.] /\left[\mathrm{CH}_{2}=\mathrm{C}\right]\right)+1=D P(\mathrm{~N})$, where the " 1 " accounts for the unsaturated end group. The degree of polymerization determined by GPC is given by $D P(\mathrm{G})$.

Table II summarizes the results of ${ }^{1} \mathrm{H}$ NMR structural analysis of the polymers, GPC measurements showing unimodal elution curves, and $k_{\mathrm{p}} / k_{\mathrm{f}}$ values obtained according to eq 1 for polymerizations of MATe together with data for MAT and MAD. ${ }^{13,15}$ At $60^{\circ} \mathrm{C}$, the values of $D P(\mathrm{G})$ and $D P(\mathrm{~N})$ increase in the order $\mathrm{MATe}<\mathrm{MAT}<\mathrm{MAD}$. If $\mathrm{AFCT}$ is the main chain stopping reaction in the MATe polymerization, $D P(\mathrm{G}) / D P(\mathrm{~N})$ which can be the efficiency of the $\omega$-end group introduction would be unity. The MATe polymerizations yielded $D P(\mathrm{G}) / D P(\mathrm{~N})=0.80\left(60^{\circ} \mathrm{C}\right)$ and $0.92\left(90^{\circ} \mathrm{C}\right)$, significantly greater than for MAT and MAD, suggesting almost quantitative introduction of the $\omega$-end groups during the MATe polymerizations. The $D P(\mathrm{G}) / D P(\mathrm{~N})$ values for MAT are considerably lower than unity, indicating that $\beta$-fragmentation is not sufficiently rapid for bimolecular termination to be negligible. ${ }^{15}$ The values of $D P(\mathrm{G})$ and $D P(\mathrm{~N})$ for MAD are much greater than for MATe and MAT, in conformity

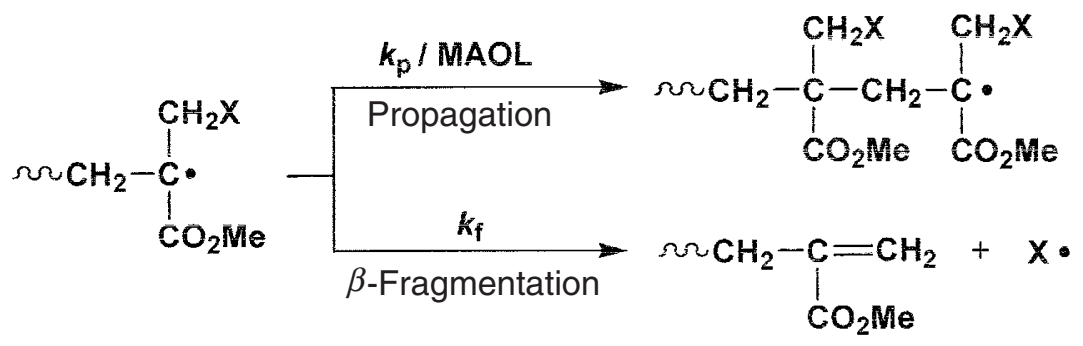

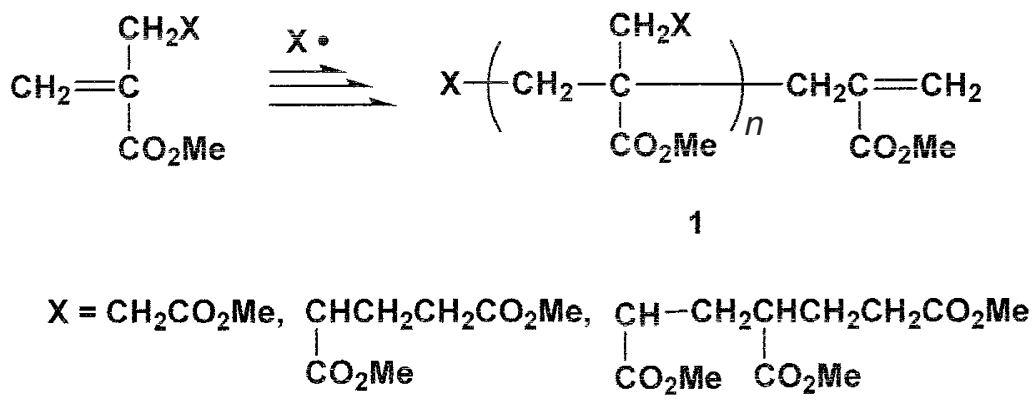

Scheme 1. 
Table II. Results of GPC and ${ }^{1} \mathrm{H}$ NMR analysis of polymers of MATe, MAT, and MAD

\begin{tabular}{|c|c|c|c|c|c|c|}
\hline \multirow{2}{*}{$\begin{array}{l}\text { MAOL } \\
(\mathrm{MW})\end{array}$} & \multirow{2}{*}{$\frac{\text { Temp. }}{{ }^{\circ} \mathrm{C}}$} & \multirow{2}{*}{ Initiator $^{\mathrm{a}}$} & \multirow{2}{*}{$\begin{array}{c}\frac{[\mathrm{MAOL} \text { unit }]}{\left[\mathrm{CH}_{2}=\mathrm{C}\right]}+1 \\
\left(=D P(\mathrm{~N})^{\mathrm{b}}\right)\end{array}$} & \multirow{2}{*}{$\frac{k_{\mathrm{p}} / k_{\mathrm{f}}}{\mathrm{L} \mathrm{mol}^{-1}}$} & \multirow{2}{*}{$\begin{array}{l}M_{\mathrm{n}} \times 10^{-3 \mathrm{c}} \\
\left(D P(\mathrm{G})^{\mathrm{d}}\right)\end{array}$} & \multirow{2}{*}{$\frac{D P(\mathrm{G})}{D P(\mathrm{~N})}$} \\
\hline & & & & & & \\
\hline $\operatorname{MATe}\left(344^{\mathrm{e}}\right)$ & 60 & AIBN & 8.4 & 2.03 & $2.3(6.68)$ & 0.80 \\
\hline MAT $\left(258^{\mathrm{e}}\right)$ & 60 & AIBN & 18 & 4.25 & $2.3(8.91)$ & 0.50 \\
\hline $\operatorname{MAD}^{\mathrm{f}}\left(172^{\mathrm{e}}\right)$ & 60 & MAIB & 1001 & 161 & $38.0(221)$ & 0.22 \\
\hline MATe & 90 & $\mathrm{ACN}$ & 6.6 & 1.75 & $2.1(6.10)$ & 0.92 \\
\hline MAT $^{\mathrm{g}}$ & 90 & $\mathrm{ACN}$ & 6.4 & 1.33 & $1.0(3.88)$ & 0.62 \\
\hline MAD $^{f}$ & 100 & ATMP & 104 & 16.6 & $13.0(76)$ & 0.73 \\
\hline
\end{tabular}

aalymerizations were carried out in bulk: [Initiator] $=0.05 \mathrm{~mol} \mathrm{~L}^{-1},[\mathrm{MATe}]=3.2 \mathrm{~mol} \mathrm{~L}^{-1}$, $[\mathrm{MAT}]=4.0 \mathrm{~mol} \mathrm{~L}^{-1}$, and $[\mathrm{MAD}]=6.2 \mathrm{~mol} \mathrm{~L}^{-1} \cdot{ }^{\mathrm{b}} D P(\mathrm{~N})$ is degree of polymerization calculated from unsaturated end group content. ${ }^{\mathrm{c}} \mathrm{Calculated}$ from unimodal elution curves showing $M_{\mathrm{w}} / M_{\mathrm{n}}=1.3-1.9 .{ }^{\mathrm{d}} D P(\mathrm{G})$ is degree of polymerization calculated from $M_{\mathrm{n}}(\mathrm{GPC})$. ${ }^{\mathrm{e}}$ Monomer molecular weight. ${ }^{\mathrm{f}}$ Ref. $15 .{ }^{\mathrm{g}}$ Ref. 13 .

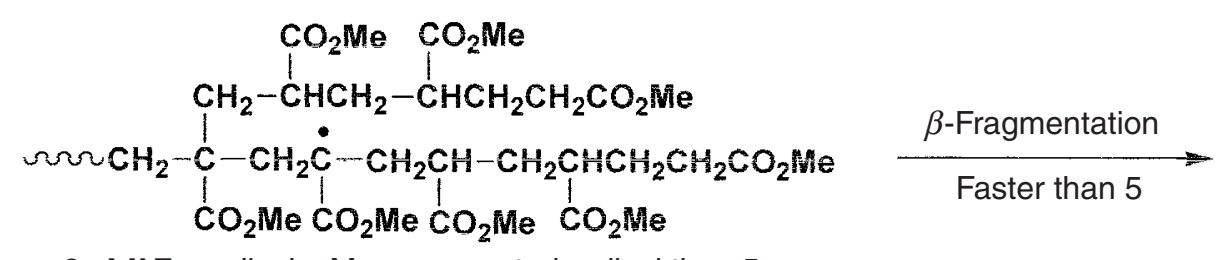

2( MATe radical): More congested radical than 5

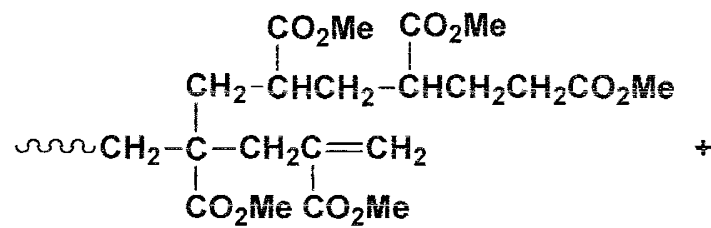

3 : More congested end structure than 6

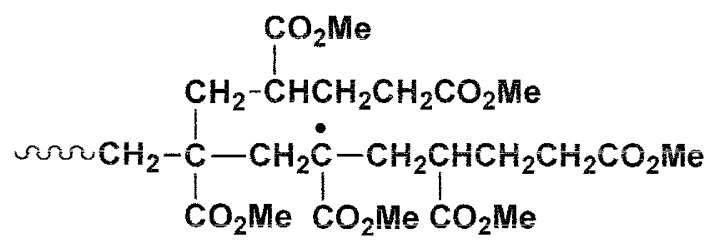

5 MAT radical): Less congested radical than 2<smiles>C=C(CCCC(=O)OC)CC(CCCCCCOC)(CC(C)=O)OC(C)=O</smiles>

6 : Less congested end structure than 3<smiles>COCCCC(CCC(C)C)OC(C)=O</smiles>

4 : Similar reactivity with 7

\section{Scheme 2.}

with faster fragmentation for MATe and MAT.

Although the MATe polymerization is slow (Table I), fragmentation of 2 can be utilized to introduce the propenyl end group by radical polymerization at $60^{\circ} \mathrm{C}$ (Scheme 2). The values of $D P(\mathrm{G}) / D P(\mathrm{~N})$ increase in the order MAD $<$ MAT $<$ MATe, revealing that the importance of bimolecular termination as an end forming event decreases in the same order. These re- sults are consistent with the values obtained for $k_{\mathrm{p}} / k_{\mathrm{f}}$, which increase as MAD $>$ MAT $>$ MATe, with the values for MAT and MATe being much lower than for MAD. This suggests that the increase in the size of the $\alpha$-substituent suppresses propagation and/or facilitates fragmentation, probably both. The situation at 90 and $100^{\circ} \mathrm{C}$ is however somewhat different; the lowest values of $k_{\mathrm{p}} / k_{\mathrm{f}}, D P(\mathrm{G}), D P(\mathrm{~N})$, and $D P(\mathrm{G}) / D P(\mathrm{~N})$ are 
here obtained for MAT, whereas the reaction behaviors for MAD and MATe are qualitatively consistent with the data at $60^{\circ} \mathrm{C}$. The value of $k_{\mathrm{p}} / k_{\mathrm{f}}$ is expected to decrease with an increase in temperature since the activation energy for fragmentation (a unimolecular reaction) is greater than for propagation (a bimolecular reaction). ${ }^{13,15,31}$ The trend in $k_{\mathrm{p}} / k_{\mathrm{f}}$ with temperature is as anticipated for MAD and MAT, but the value for MATe decreases much less than expected upon a temperature increase by as much as $30^{\circ} \mathrm{C}$. It should be recalled that the increase in the size of the $\alpha$-substituent from MAD to MAT resulted in a decrease in the activation energy for the fragmentation. ${ }^{15}$

The similarity in the structures of the end groups and MAOL, in particular MATe, deserves attention. The $k_{\mathrm{p}} / k_{\mathrm{f}}$ value for MATe being slightly greater than that for MAT at $90^{\circ} \mathrm{C}$ in Table II suggests consumption of end groups by further reaction with propagating and expelled radicals in the case of MATe, leading to incorporation of the macromonomer moiety (7 in Scheme 2). More precisely, the data suggest that the extent of end group reaction is greater for MATe than for MAT. Steric congestions of the end groups ( $\mathbf{3}$ and $\mathbf{6}$ ) and the radical centers ( $\mathbf{2}$ and $\mathbf{5}$ ) are compared in Scheme 2.

The reason for this is thought to be that the end group formed by fragmentation during MATe polymerization $\mathbf{6}$ is similarly or less congested than monomeric MATe. Although fragmentation of the MATe radical 2 to form poly(MATe) bearing the propenyl end group 3 and the small radical 4 is facilitated relative to propagation by an increase in temperature from 60 to $90^{\circ} \mathrm{C}, 3$ might be consumed by further reaction with 2 and 4 leading to an increase in [MATe unit] $/\left[\mathrm{CH}_{2}=\mathrm{C}\right.$ group], and thus underestimation of the true $k_{\mathrm{p}} / k_{\mathrm{f}}$ value. In the case of MAT, on the other hand, the end group attached to the poly(MAT) chain $\mathbf{6}$ would be less reactive than monomeric MAT because the poly(MAT) chain and the $\mathrm{C}_{4}$-group bearing two carbomethoxy groups are bound to the double bond as the $\alpha$-substituents. The $\omega$-end groups of poly(MAT) were found to be involved in further reactions during the MAT polymerization resulting in bimodal GPC curves. ${ }^{15}$

\section{Copolymerization}

Radical 2 readily undergoes $\beta$-fragmentation to yield polymer consisting of the MATe units and $\mathbf{3}$. It was confirmed by inspection of the ${ }^{1} \mathrm{H}$ NMR spectra of the copolymers of MATe and MAT (Figures 2 and 3 ), which exhibit resonances assigned to the olefinic protons of the end group that 2 undergoes rapid $\beta$ fragmentation also during copolymerization. Results of copolymerizations of MATe, MAT, and MAD ${ }^{14}$ with CHA are summarized in Table III. The monomer reac-

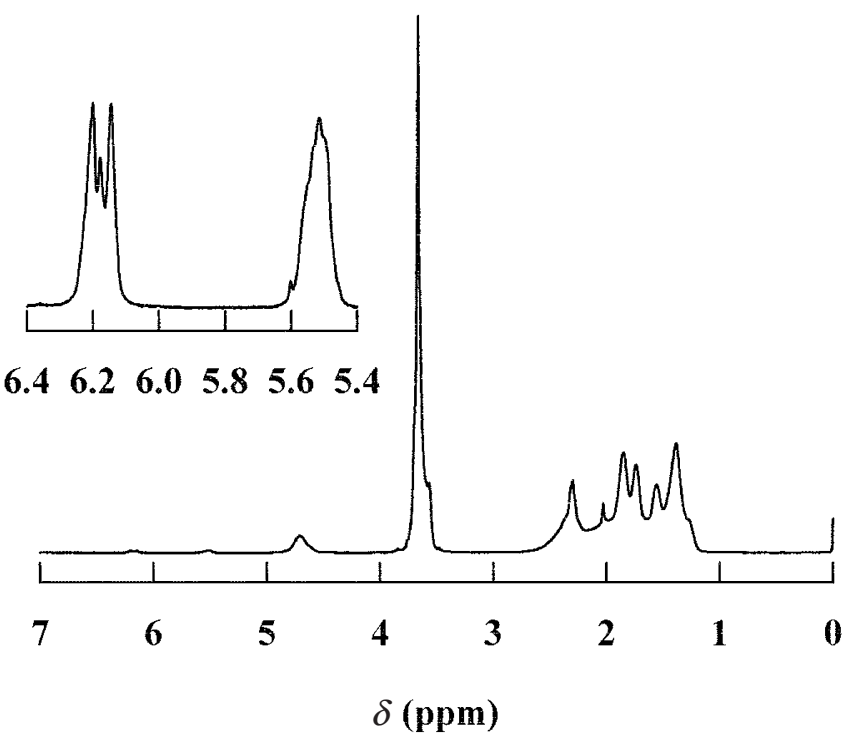

Figure 2. ${ }^{1} \mathrm{H}$ NMR spectrum of CHA-MATe copolymer $\left(M_{\mathrm{n}}=4100\right)$ prepared by copolymerization in benzene for $3 \mathrm{~h}$ at $90{ }^{\circ} \mathrm{C}$ under the conditions of $[\mathrm{MATe}]=1.0 \mathrm{~mol} \mathrm{~L}^{-1},[\mathrm{CHA}]=$ $1.0 \mathrm{~mol} \mathrm{~L}^{-1}$, and $[\mathrm{ACN}]=5.0 \mathrm{mmol} \mathrm{L}^{-1}$.

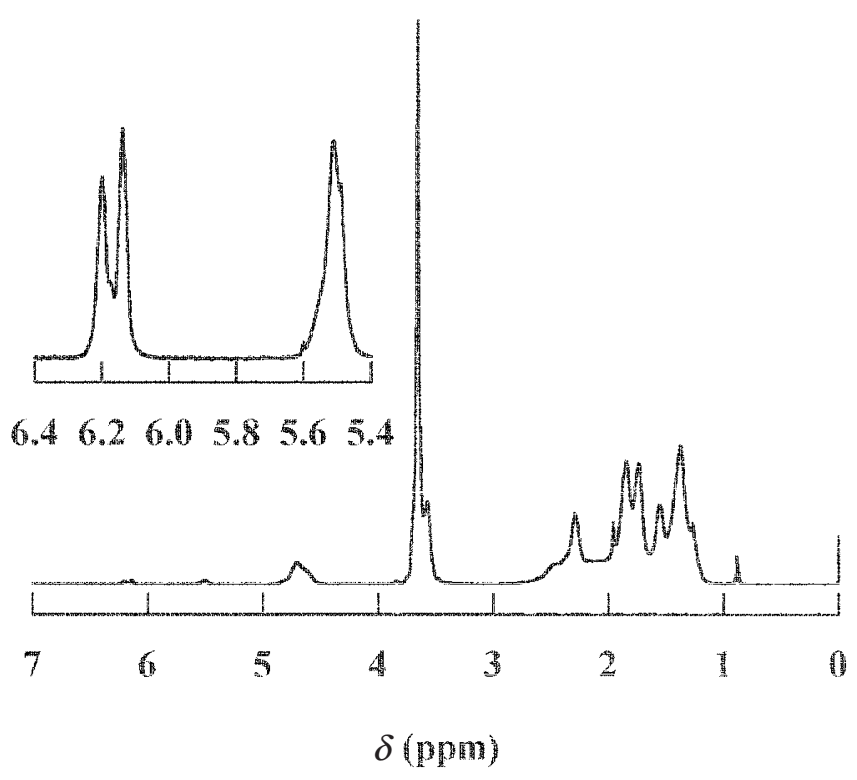

Figure 3. ${ }^{1} \mathrm{HNMR}$ spectrum of CHA-MAT copolymer $\left(M_{\mathrm{n}}=3200\right)$ prepared by copolymerization in benzene for $2 \mathrm{~h}$ at $90^{\circ} \mathrm{C}$ under the conditions of $[\mathrm{MAT}]=1.0 \mathrm{~mol} \mathrm{~L}^{-1},[\mathrm{CHA}]=$ $1.0 \mathrm{~mol} \mathrm{~L}^{-1}$, and $[\mathrm{ACN}]=5.0 \mathrm{mmol} \mathrm{L}^{-1}$.

tivity ratios were calculated from the copolymer compositions data obtained at low conversions $(<10 \%)$ (Figure 4$)$. The quantity $1 / r_{1}\left(\mathrm{M}_{1}=\mathrm{CHA}, \mathrm{M}_{2}=\mathrm{MAOL}\right)$ denotes the reactivities of MATe, MAT, and MAD toward the poly(CHA) radical relative to $\mathrm{CHA}$. The CHA-terminated radicals add more rapidly to the MAOLs than to CHA, consistent with the propenyl end groups being as reactive as acrylic ester and styrene toward the respective propagating radicals. ${ }^{22}$ MATe and MAT are slightly less reactive than MAD towards the 
Table III. Monomer reactivity ratios and GPC data for copolymerization of CHA $\left(\mathrm{M}_{1}\right)$ with MATe, MAT, and MAD $\left(\mathrm{M}_{2}\right)$

\begin{tabular}{|c|c|c|c|c|c|c|c|}
\hline $\mathrm{M}_{2}$ & $\frac{\text { Temp. }}{{ }^{\circ} \mathrm{C}}$ & $r_{1}$ & $r_{2}$ & $1 / r_{1}$ & $1 / r_{2}$ & ${\frac{M_{\mathrm{n}}(\mathrm{G})^{\mathrm{a}}}{M_{\mathrm{n}}(\mathrm{N})}}$ & Ref \\
\hline MATe & 60 & 0.83 & 0.71 & 1.20 & 1.41 & $0.70^{\mathrm{b}}$ & This work \\
\hline MAT & 60 & 0.83 & 0.56 & 1.20 & 1.79 & 0.60 & 15 \\
\hline MAD & 60 & 0.68 & 1.28 & 1.47 & 0.78 & 0.44 & 14 \\
\hline MATe & 90 & 0.86 & 0.63 & 1.16 & 1.58 & $0.88^{\mathrm{c}}$ & This work \\
\hline MAT & 90 & 0.96 & 0.47 & 1.04 & 2.13 & 0.72 & This work \\
\hline MAD & 100 & 0.66 & 1.00 & 1.52 & 1.00 & 0.62 & 14 \\
\hline
\end{tabular}

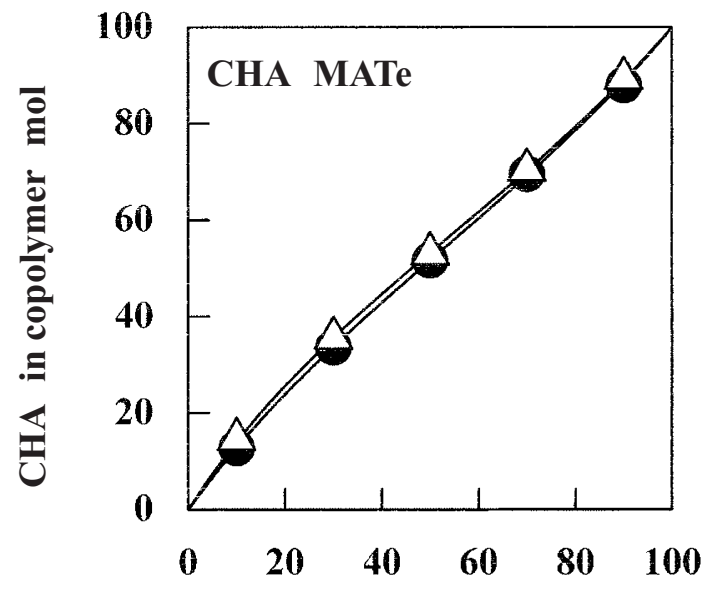

[CHA ] in comonomer $(\mathrm{mol} \%)$

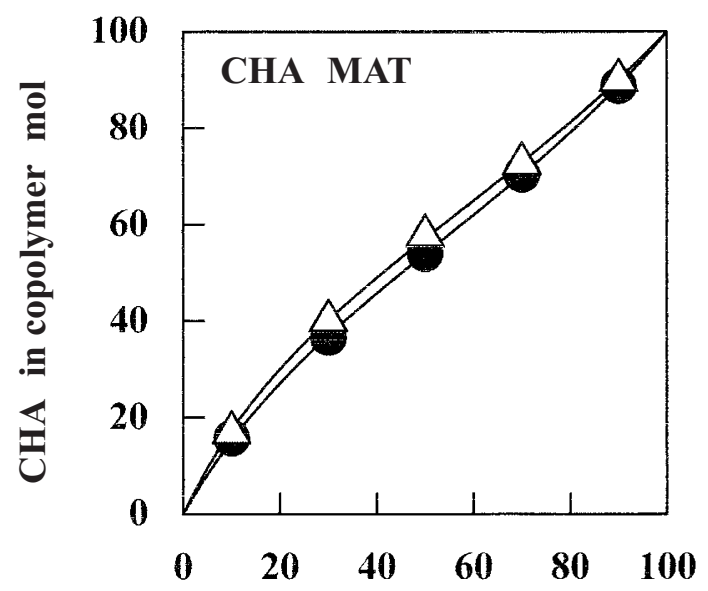

[CHA ] in comonomer $(\operatorname{mol} \%)$

Figure 4. Copolymer compositions curves for copolymerizations of CHA $\left(\mathrm{M}_{1}\right)$ with MATe and MAT $\left(\mathrm{M}_{2}\right)$ at $60(\bullet)$ and $90^{\circ} \mathrm{C}$ $(\triangle)$.

poly(CHA) radical in accordance with the size of the $\alpha$-substituents.

The value of $1 / r_{2}$ represents the reactivity of CHA towards poly(MAOL) radicals such as $\mathbf{2}$ or $\mathbf{5}$ (Scheme 2) relative to MAOL. The $r_{2}$ values are less than unity for the copolymerizations with MATe and MAT indicating that CHA is somewhat more reactive than MAOL towards the corresponding poly(MAOL) radicals. In the case of MATe, the $1 / r_{2}$ value at 60 and $90^{\circ} \mathrm{C}$ indicates that CHA is more reactive than MATe itself by factors of only 1.41 and 1.58 , respectively. Considering the large differences in $k_{\mathrm{p}}$ values between MAOL ( $k_{\mathrm{p}}$ for MAD and MAT at $60^{\circ} \mathrm{C}$ are 19 and $2.43 \mathrm{~L} \mathrm{~mol}^{-1} \mathrm{~s}^{-1}$, respectively $)^{13,15,16}$ and CHA $\left(k_{\mathrm{p}}=16000 \mathrm{~L} \mathrm{~mol}^{-1} \mathrm{~s}^{-1}\right.$ at $\left.30^{\circ} \mathrm{C}\right),{ }^{32}$ large differences in the $k_{12}$ and $k_{21}$ values can be predicted. Although $1 / r_{1}$ for the copolymerization of CHA with MAD are greater than unity, the $1 / r_{2}$ values are $0.78\left(60^{\circ} \mathrm{C}\right)$ and $1.00\left(100^{\circ} \mathrm{C}\right)$ showing that $\mathrm{CHA}$ is as reactive as MAD toward the poly(MAD) radical.

The values of $1 / r_{1}$ are relatively unaffected by a temperature increase from 60 to $90^{\circ} \mathrm{C}$ for MAD and MATe, although a decrease is observed for MAT. An increase in temperature for the MAT and MATe copolymerizations causes less incorporation of MAOL units into the copolymers relative to CHA, as seen in the observed increases in $r_{1}$ and decreases in $r_{2}$. This may be related to the ceiling temperatures for homopropagation of MAT and MATe being close to $90^{\circ} \mathrm{C}$ under the copolymerization conditions. ${ }^{13,15}$ As mentioned earlier, the efficiency of unsaturated end group introduction can be assessed by examination of the quantity $M_{\mathrm{n}}(\mathrm{G}) / M_{\mathrm{n}}(\mathrm{N})$, which approaches unity as the efficiency increases. For all MAOLs, $M_{\mathrm{n}}(\mathrm{G}) / M_{\mathrm{n}}(\mathrm{N})$ increases with temperature consistent with higher temperatures favoring fragmentation relative to propagation. Moreover, at both 60 and $90^{\circ} \mathrm{C}, M_{\mathrm{n}}(\mathrm{G}) / M_{\mathrm{n}}(\mathrm{N})$ increases with the size of the $\alpha$-substituent of MAOL, i.e., in the order MAD $<$ MAT $<$ MATe, indicating suppressed propagation and/or increased rates of fragmentation in the same order.

Results of copolymerizations of MATe and MAT with CHA over a wide range of monomer feed compositions at 60 and $90^{\circ} \mathrm{C}$ are summarized in Table IV 
Table IV. Results of copolymerizations at $60^{\circ} \mathrm{C}$

\begin{tabular}{ccccccc}
\hline $\begin{array}{c}{\left[\mathrm{M}_{2}\right] \text { in }} \\
\text { comonomer }\end{array}$ & \multicolumn{3}{c}{$\begin{array}{c}\mathrm{CHA}\left(\mathrm{M}_{1}\right)-\mathrm{MATe}\left(\mathrm{M}_{2}\right)^{\mathrm{a}} \\
\left(r_{\mathrm{CHA}}=0.83, r_{\mathrm{MATe}}=0.71\right)\end{array}$} & \multicolumn{2}{c}{$\begin{array}{c}\mathrm{CHA}\left(\mathrm{M}_{1}\right)-\mathrm{MAT}\left(\mathrm{M}_{2}\right)^{\mathrm{a}} \\
\left(r_{\mathrm{CHA}}=0.83, r_{\mathrm{MAT}}=0.50\right)\end{array}$} \\
\cline { 2 - 5 }$\left(\begin{array}{c}\left.M_{\mathrm{n}} \times 10^{-3 \mathrm{~b}}\right) \\
(\mathrm{GPC})\end{array}\right.$ & $\frac{[\mathrm{MATe} \text { unit }]}{\left[\mathrm{CH}_{2}=\mathrm{C}\right]}$ & $\frac{P_{\mathrm{n}}(\mathrm{MATe})}{P_{\mathrm{n}}(\mathrm{CHA})}$ & $\begin{array}{c}M_{\mathrm{n}} \times 10^{-3 \mathrm{c}} \\
(\mathrm{GPC})\end{array}$ & $\frac{[\mathrm{MAT} \text { unit }]}{\left[\mathrm{CH}_{2}=\mathrm{C}\right]}$ & $\frac{P_{\mathrm{n}}(\mathrm{MAT})}{P_{\mathrm{n}}(\mathrm{CHA})}$ \\
\hline 5 & $76.1^{\mathrm{d}}$ & $87.7^{\mathrm{d}}$ & $13.7 / 463$ & $144.5^{\mathrm{d}}$ & $87.6^{\mathrm{d}}$ & $36.4 / 876$ \\
10 & 34.8 & 23.9 & $12.1 / 199$ & 54.5 & 44.8 & $23.6 / 314$ \\
30 & 9.3 & 18.6 & $8.2 / 42.0$ & 11.5 & 29.9 & $13.2 / 52.5$ \\
50 & 4.8 & 14.1 & $6.7 / 16.1$ & 5.7 & 21.5 & $10.2 / 20.0$ \\
70 & 3.3 & 11.2 & $6.4 / 7.2$ & 2.4 & 11.5 & $5.9 / 5.7$ \\
90 & 2.3 & 8.7 & $5.8 / 1.9$ & 1.9 & 9.1 & $5.2 / 1.6$ \\
\hline
\end{tabular}

${ }^{\mathrm{a}}\left[\mathrm{M}_{1}\right]+\left[\mathrm{M}_{2}\right]=2 \mathrm{~mol} \mathrm{~L}^{-1}$ and $[\mathrm{AIBN}]=5 \mathrm{mmol} \mathrm{L}^{-1}$. ${ }^{\mathrm{b}}$ Calculated from unimodal elution curves showing $M_{\mathrm{w}} / M_{\mathrm{n}}=1.5-2.0$. ${ }^{\circ}$ Calculated from unimodal elution curves showing $M_{\mathrm{w}} / M_{\mathrm{n}}=1.4-2.5$. ${ }^{\mathrm{d}}\left[\mathrm{M}_{1}\right]+\left[\mathrm{M}_{2}\right]=3 \mathrm{~mol} \mathrm{~L}^{-1}$ and $[\mathrm{AIBN}]=5 \mathrm{mmol} \mathrm{L}^{-1}$.

Table V. Results of copolymerization of MATe and MAT at $90^{\circ} \mathrm{C}^{\text {a }}$

\begin{tabular}{|c|c|c|c|c|c|c|}
\hline $\begin{array}{l}{\left[\mathrm{M}_{2}\right] \text { in }} \\
\text { comonomer }\end{array}$ & \multicolumn{3}{|c|}{$\begin{array}{c}\text { CHA }\left(\mathrm{M}_{1}\right)-\mathrm{MATe}\left(\mathrm{M}_{2}\right) \\
\left(r_{\mathrm{CHA}}=0.86, r_{\mathrm{MATe}}=0.63\right) \\
\end{array}$} & \multicolumn{3}{|c|}{$\begin{array}{c}\mathrm{CHA}\left(\mathrm{M}_{1}\right)-\mathrm{MAT}\left(\mathrm{M}_{2}\right) \\
\left(r_{\mathrm{CHA}}=0.96, r_{\mathrm{MAT}}=0.47\right)\end{array}$} \\
\hline$(\mathrm{mol} \%)$ & $\begin{array}{l}\overline{M_{\mathrm{n}} \times 10^{-3 \mathrm{~b}}} \\
(\mathrm{GPC})\end{array}$ & $\frac{[\text { MATe unit }]}{\left[\mathrm{CH}_{2}=\mathrm{C}\right]}$ & $\frac{P_{\mathrm{n}}(\mathrm{MAT})}{P_{\mathrm{n}}(\mathrm{CHA})}$ & $\begin{array}{l}\overline{M_{\mathrm{n}} \times 10^{-3 \mathrm{~d}}} \\
\quad(\mathrm{GPC})\end{array}$ & $\frac{[\text { MAT unit }]}{\left[\mathrm{CH}_{2}=\mathrm{C}\right]}$ & $\frac{P_{\mathrm{n}}(\mathrm{MAT})}{P_{\mathrm{n}}(\mathrm{CHA})}$ \\
\hline 10 & 24.4 & 23.7 & $7.5 / 142$ & 24.2 & 24.2 & $9.5 / 141$ \\
\hline 30 & 6.8 & 14.6 & $5.8 / 31$ & 6.6 & 15.5 & $7.0 / 31$ \\
\hline 50 & 4.1 & 10.7 & $5.9 / 14$ & 3.2 & 10.1 & $5.2 / 12$ \\
\hline 70 & 3.0 & 7.9 & $5.6 / 6.9$ & 1.8 & 6.9 & $4.2 / 4.7$ \\
\hline 90 & 2.3 & 6.4 & $5.7 / 2.2$ & 1.2 & 5.1 & $3.9 / 1.3$ \\
\hline
\end{tabular}

${ }^{\mathrm{a}}[\mathrm{CHA}]+\left[\mathrm{M}_{2}\right]=2 \mathrm{~mol} \mathrm{~L}^{-1}$ and $[\mathrm{AIBN}]=5 \mathrm{mmol} \mathrm{L}^{-1} \cdot{ }^{\mathrm{b}}$ Calculated from unimodal elution curves showing $M_{\mathrm{w}} / M_{\mathrm{n}}=1.4-1.9$. ${ }^{\mathrm{c}}$ Calculated from copolymer composition and $M_{\mathrm{n}}(\mathrm{GPC}) .{ }^{\mathrm{d}}$ Calculated from unimodal elution curves showing $M_{\mathrm{w}} / M_{\mathrm{n}}=1.3-1.6$.

Table VI. Results of CHA $\left(\mathrm{M}_{1}\right)-\mathrm{MAD}\left(\mathrm{M}_{2}\right)$ copolymerizations ${ }^{\mathrm{a}}$ at 60 and $100^{\circ} \mathrm{C}$

\begin{tabular}{|c|c|c|c|c|c|c|}
\hline $\begin{array}{l}{\left[\mathrm{M}_{2}\right] \text { in }} \\
\text { comonomer }\end{array}$ & \multicolumn{3}{|c|}{$\begin{array}{c}60^{\circ} \mathrm{C}^{\mathrm{b}} \\
\left(_{\mathrm{CHA}}=0.68, r_{\mathrm{MAD}}=1.28\right)\end{array}$} & \multicolumn{3}{|c|}{$\begin{array}{c}100^{\circ} \mathrm{C}^{\mathrm{c}} \\
\left.r_{\mathrm{CHA}}=0.66, r_{\mathrm{MAD}}=1.00\right)\end{array}$} \\
\hline$(\mathrm{mol} \%)$ & $\begin{array}{l}M_{\mathrm{n}} \times 10^{-3 \mathrm{~d}} \\
(\mathrm{GPC})\end{array}$ & $\frac{[\mathrm{MAD} \text { unit }]}{\left[\mathrm{CH}_{2}=\mathrm{C}\right]}$ & $\frac{P_{\mathrm{n}}(\mathrm{MAD})}{P_{\mathrm{n}}(\mathrm{CHA})}$ & $\begin{array}{c}M_{\mathrm{n}} \times 10^{-3 \mathrm{e}} \\
(\mathrm{GPC})\end{array}$ & $\frac{[\mathrm{MAD} \text { unit }]}{\left[\mathrm{CH}_{2}=\mathrm{C}\right]}$ & $\frac{P_{\mathrm{n}}(\mathrm{MAD})}{P_{\mathrm{n}}(\mathrm{CHA})}$ \\
\hline 10 & 150 & - & $74 / 527$ & 67 & 135 & $12 / 84$ \\
\hline 30 & 53 & 359 & $89 / 169$ & 17.4 & 29.9 & $36 / 72$ \\
\hline 50 & 37 & 173 & $76 / 62$ & 9.1 & 21.5 & $30 / 26$ \\
\hline 70 & 20 & 143 & $72 / 25$ & 6.9 & 11.5 & $29 / 12$ \\
\hline 90 & 13 & 101 & $64 / 6$ & 4.3 & 9.1 & $23 / 3$ \\
\hline
\end{tabular}

${ }^{\mathrm{a}}\left[\mathrm{M}_{1}\right]+\left[\mathrm{M}_{2}\right]=2 \mathrm{~mol} \mathrm{~L}^{-1} \cdot{ }^{\mathrm{b}}[\mathrm{MAIB}]=10 \mathrm{mmol} \mathrm{L}^{-1} \cdot{ }^{\mathrm{c}}[\mathrm{ATMP}]=10 \mathrm{mmol} \mathrm{L}{ }^{-1} \cdot{ }^{\mathrm{d}}$ Calculated from unimodal elution curves showing $M_{\mathrm{w}} / M_{\mathrm{n}}=1.6-1.8$. ${ }^{\mathrm{e}}$ Calculated from unimodal elution curves showing $M_{\mathrm{w}} / M_{\mathrm{n}}=1.6-3.0$.

and $\mathrm{V}$, respectively. For comparison, the results of the copolymerization with MAD reported in our previous paper are shown in Table VI. ${ }^{14}$ An increase in the MATe or MAT content in the monomer feed results in a reduction in $M_{\mathrm{n}}$ because of the AFCT function of MAOL. An increase in CHA content in the monomer feed facilitated incorporation of a larger amount of MAOL as monomer units to increase the [MAOL unit] $/\left[\mathrm{CH}_{2}=\mathrm{C}\right]$ value because simultaneous addition of poly(MAOL) radicals to CHA and MAOL decreases the fragmentation of poly(MAOL) radicals relative to propagation. The copolymer composition given by the number of monomer units per chain, $P_{\mathrm{n}}(\mathrm{MAOL}) / P_{\mathrm{n}}(\mathrm{CHA})$, increases in the order of MATe $<$ MAT $<$ MAD at 60 and 
$90{ }^{\circ} \mathrm{C}$. This can be explained by the $r_{1}$ and $r_{2}$ values together with the AFCT function of MAOL. The value of [MATe unit] $/\left[\mathrm{CH}_{2}=\mathrm{C}\right]$ is almost the same as [MAT unit $] /\left[\mathrm{CH}_{2}=\mathrm{C}\right]$ at each comonomer composition at both temperatures. The values of [MATe unit] $/\left[\mathrm{CH}_{2}=\mathrm{C}\right]$ and [MAT unit] $/\left[\mathrm{CH}_{2}=\mathrm{C}\right]$ are consistently higher at 60 than $90^{\circ} \mathrm{C}$, indicating that the rate of fragmentation relative to crosspropagation increase with temperature.

The value of $k_{22} / k_{\mathrm{f}}$ for copolymerization, corresponding to $k_{\mathrm{p}} / k_{\mathrm{f}}$ for homopolymerization, was evaluated using eq 2 , which can be derived in analogy with eq 1 by considering competition between propagation and $\beta$-fragmentation. ${ }^{13,14}$ It was assumed that penultimate effects on propagation and fragmentation are negligible.

$$
\begin{aligned}
& \frac{[\mathrm{MAOL} \text { unit }]}{\left[\mathrm{CH}_{2}=\mathrm{C}\right]} \\
& =\frac{k_{21}[\mathrm{MAOL} \cdot]\left[\mathrm{M}_{1}\right]+k_{22}[\mathrm{MAOL} \cdot][\mathrm{MAOL}]}{k_{\mathrm{f}}[\mathrm{MAOL} \cdot]} \\
& \frac{[\mathrm{MAOL} \text { unit }]}{\left[\mathrm{CH}_{2}=\mathrm{C}\right][\mathrm{MAOL}]} \\
& =\frac{k_{22}}{k_{\mathrm{f}}}+\frac{k_{21}\left[\mathrm{M}_{1}\right]}{k_{\mathrm{f}}[\mathrm{MAOL}]}=\frac{k_{22}}{k_{\mathrm{f}}}\left(\frac{\left[\mathrm{M}_{1}\right]}{r_{2}[\mathrm{MAOL}]}+1\right)
\end{aligned}
$$

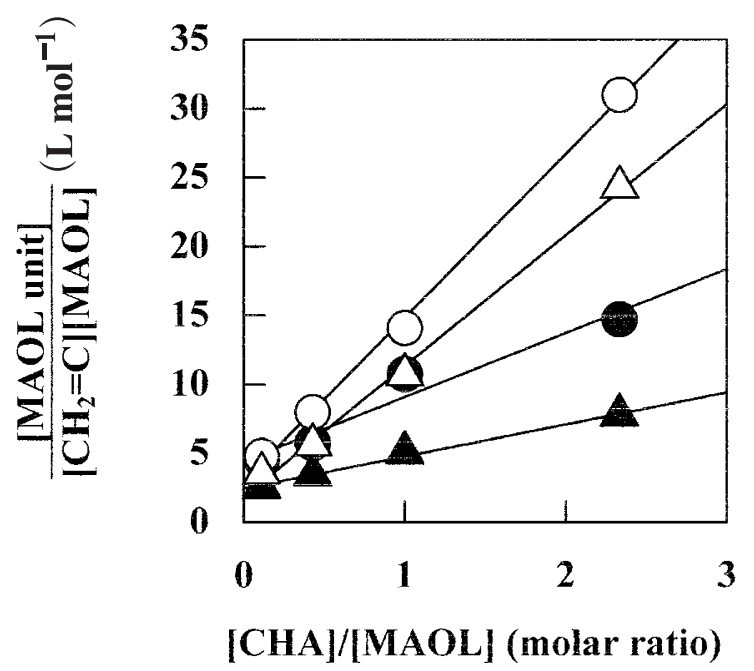

Figure 5. Plots of $[\mathrm{MAOL}$ unit $] /\left[\mathrm{CH}_{2}=\mathrm{C}\right][\mathrm{MAOL}] \quad v s$. $[\mathrm{CHA}] /[\mathrm{MAOL}]$ according to eq 2 for copolymerization of MAOL with CHA at 60 (MAT; $\bullet$, MATe; $\bigcirc$ ) and $90^{\circ} \mathrm{C}(\mathrm{MAT} ; \boldsymbol{\Delta}$, MAT; $\triangle)$.
Plots according to eq 3 for copolymerizations of MATe and MAT with CHA at $90^{\circ} \mathrm{C}$ are shown in Figure 5, and Table VII lists the values of $k_{22} / k_{\mathrm{f}}$ obtained from the y-intercepts. Although a significant difference between $k_{\mathrm{p}} / k_{\mathrm{f}}$ for the homopolymerizations of MATe and MAT was observed at $60^{\circ} \mathrm{C}$ (Table II), the $k_{22} / k_{\mathrm{f}}$ values for the CHA copolymerizations of MATe and MAT are the same at both 60 and $90^{\circ} \mathrm{C}$ suggesting underestimation of the $k_{22} / k_{\mathrm{f}}$ values arising from consumption of the end group by further reaction (Table VII). The $k_{22} / k_{\mathrm{f}}$ values for MAD are considerably greater than those for MATe and MAT, indicating that the MATe and MAT radicals undergo faster fragmentation than the radical from MAD not only in homopolymerization but also in copolymerization with CHA. The $k_{\mathrm{p}} / k_{\mathrm{f}}$ values (Table II), the $M_{\mathrm{n}}(\mathrm{G}) / M_{\mathrm{n}}(\mathrm{N})$ values (Table III), and the $k_{22} / k_{\mathrm{f}}$ values (Table VII) reveal that the propenyl end groups are almost quantitatively introduced in the copolymers involving MATe at 60 and $90^{\circ} \mathrm{C}$, and by the copolymerization with MAT at $90^{\circ} \mathrm{C}$. Finally, it is also noteworthy that the slopes (i.e., $k_{2} / k_{\mathrm{f}}$ ) decrease with increasing temperature as expected, and that $k_{2} / k_{\mathrm{f}}$ (MATe) $>k_{21} / k_{\mathrm{f}}$ (MAT), suggesting that fragmentation is faster and/or crosspropagation is slower for MATe than for MAT.

\section{CONCLUSIONS}

MATe homopolymerization and copolymerization with CHA have been studied with the focus on macromonomer formation by $\beta$-fragmentation of the MATe propagating radical. The results were compared with polymerizations and copolymerizations of MAT and MAD, as summarized in Table VIII with brief remarks. The ratio of the degree of polymerization determined by GPC $(D P(\mathrm{G}))$ to that calculated from the end group content $(D P(\mathrm{~N}))$ denotes the efficiency of end group introduction. The ratios of the rate constants for propagation to fragmentation $\left(k_{\mathrm{p}} / k_{\mathrm{f}}\right)$, which closely relates to $D P(\mathrm{G}) / D P(\mathrm{~N})$, were evaluated to show the

\begin{tabular}{|c|c|c|c|c|c|c|c|}
\hline \multirow{2}{*}{$\begin{array}{c}\text { MAOL } \\
\left(\mathrm{M}_{2}\right)\end{array}$} & \multicolumn{3}{|c|}{$k_{22} / k_{\mathrm{f}}\left(\mathrm{L} \mathrm{mol}^{-1}\right)$} & \multicolumn{3}{|c|}{$k_{21} / k_{\mathrm{f}}\left(\mathrm{L} \mathrm{mol}^{-1}\right)$} & \multirow{2}{*}{ Ref } \\
\hline & $\overline{60^{\circ} \mathrm{C}}$ & $90^{\circ} \mathrm{C}$ & $100^{\circ} \mathrm{C}$ & $60^{\circ} \mathrm{C}$ & $90^{\circ} \mathrm{C}$ & $100^{\circ} \mathrm{C}$ & \\
\hline MATe & 4.5 & 3.1 & - & 11.9 & 9.5 & - & $\begin{array}{l}\text { This } \\
\text { work }\end{array}$ \\
\hline MAT & 4.4 & 3.1 & - & 4.6 & 2.3 & - & $\begin{array}{l}\text { This } \\
\text { work }\end{array}$ \\
\hline MAD & 82.8 & - & 20.0 & 115 & - & 31.6 & 14 \\
\hline
\end{tabular}
balance between the two reactions. The end groups were introduced almost quantitatively in poly(MATe) at low conversion at 60 and $90^{\circ} \mathrm{C}$. The values of $1 / r_{1}$

Table VII. $k_{22} / k_{\mathrm{f}}$ and $k_{21} / k_{\mathrm{f}}$ values for copolymerizations of CHA $\left(\mathrm{M}_{1}\right)$ with MATe, MAT, and MAD $\left(\mathrm{M}_{2}\right)$ 
Macromonomer Preparation by Radical Polymerization

Table VIII. Comparison of MATe, MAT, and MAD from different points of view

\begin{tabular}{|c|c|c|}
\hline Item & Observed order & Factors considered \\
\hline $\begin{array}{l}D P(\mathrm{G}) / D P(\mathrm{~N}) \text { at } \\
60^{\circ} \mathrm{C}\end{array}$ & MATe $>$ MAT $>$ MAD & $\begin{array}{l}\text { Facilitation of fragmentation as the main } \\
\text { end forming reaction by } \alpha \text {-substituent. }\end{array}$ \\
\hline $\begin{array}{l}D P(\mathrm{G}) / D P(\mathrm{~N}) \text { at } \\
90^{\circ} \mathrm{C}\end{array}$ & MATe $>$ MAD $\left(100^{\circ} \mathrm{C}\right)>$ MAT & $\begin{array}{l}\text { Facilitation of fragmentation by } \alpha \text {-sub- } \\
\text { stituent }+ \text { Further reaction of end group } \\
\text { formed. }\end{array}$ \\
\hline$k_{\mathrm{p}} / k_{\mathrm{f}}$ at $60^{\circ} \mathrm{C}$ & MATe $<$ MAT $<$ MAD & $\begin{array}{l}\text { Decrease and increase in } k_{\mathrm{p}} \text { and } k_{\mathrm{f}} \text {, respec- } \\
\text { tively, by } \alpha \text {-substituent. }\end{array}$ \\
\hline$k_{\mathrm{p}} / k_{\mathrm{f}}$ at $90^{\circ} \mathrm{C}$ & MAT $<$ MATe $<\operatorname{MAD}\left(100^{\circ} \mathrm{C}\right)$ & $\begin{array}{l}\text { Decrease and increase in } k_{\mathrm{p}} \text { and } k_{\mathrm{f}} \text {, respec- } \\
\text { tively, by } \alpha \text {-substituent }+ \text { Further reaction } \\
\text { of end group formed }\end{array}$ \\
\hline $1 / r_{1}$ at $60^{\circ} \mathrm{C}$ & $\mathrm{MATe}=\mathrm{MAT}<\mathrm{MAD}$ & $\begin{array}{l}\text { Decrease in reactivity toward poly(CHA) } \\
\text { radical by } \alpha \text {-substituent. }\end{array}$ \\
\hline $1 / r_{1}$ at $90^{\circ} \mathrm{C}$ & MAT $<$ MATe $<\operatorname{MAD}\left(100^{\circ} \mathrm{C}\right)$ & $\begin{array}{l}\text { Decrease in reactivity toward poly(CHA) } \\
\text { radical by } \alpha \text {-substituent }+ \text { Further reaction } \\
\text { of end group after fragmentation. }\end{array}$ \\
\hline $1 / r_{2}$ at $60^{\circ} \mathrm{C}$ & MAT $>$ MATe $>$ MAD & $\begin{array}{l}\text { Decrease in } k_{22} \text { by bulky by } \alpha \text {-substituent } \\
\text { of propagating radical + Further reaction of } \\
\text { end group after fragmentation. }\end{array}$ \\
\hline $1 / r_{2}$ at $90^{\circ} \mathrm{C}$ & MAT $>$ MATe $>$ MAD $\left(100^{\circ} \mathrm{C}\right)$ & $\begin{array}{l}\text { Decrease in } k_{22} \text { by } \alpha \text {-substituent of prop- } \\
\text { agating radical }+ \text { Further reaction of end } \\
\text { group after fragmentation. }\end{array}$ \\
\hline$k_{22} / k_{\mathrm{f}}$ at $60^{\circ} \mathrm{C}$ & $\mathrm{MAD} \gg \mathrm{MATe} \sim \mathrm{MAT}$ & $\begin{array}{l}\text { Increase in } k_{\mathrm{f}} \text { by internal strain arising } \\
\text { from } \alpha \text {-substituent }+ \text { Further reaction of end } \\
\text { group after fragmentation. }\end{array}$ \\
\hline
\end{tabular}

and $1 / r_{2}$ were calculated from the monomer reactivity ratios to estimate the steric hindrance of the additions of the poly(CHA) radical to MATe and MAT, and for the additions of the corresponding propagating radicals to CHA. The $\alpha$-substituents of MATe and MAT appear to suppress addition despite the acceleration of the $\beta$-fragmentation. Consequently, copolymerization of MATe with CHA was confirmed to be an efficient route to prepare macromonomer bearing the propenyl end group. However, the end group introduced to poly(MATe) copolymerizes with MATe since the level of steric congestion of the end group is similar to that of monomeric MATe.

Acknowledgment. Financial support from Toagosei Co., Ltd. is gratefully acknowledged.

\section{REFERENCES}

1. J. Penelle, J. Collot, and G. Rufford, J. Polym. Sci., Part A: Polym. Chem., 31, 2407 (1993).
2. S. Kobatake and B. Yamada, Polym. J., 28, 535 (1996).

3. B. Yamada and S. Kobatake, Prog. Polym. Sci., 19, 1089 (1994).

4. B. Yamada, D. G. Westmoreland, S. Kobatake, and O. Konosu, Prog. Polym. Sci., 24, 565 (1999).

5. B. Yamada and S. Kobatake, Polym. J., 24, 281 (1992).

6. G. F. Meijs, E. Rizzardo, and S. H. Thang, Polym. Bull., 24, 501 (1990).

7. S. A. F. Bon, S. R. Morseley, C. Waterson, and D. F. M. Haddleton, Macromolecules, 33, 5819 (2000).

8. G. F. Meijs, E. Rizzardo, and S. H. Thang, Macromolecules, 21, 3122 (1988).

9. G. F. Meijs, T. C. Morton, E. Rizzardo, and S. H. Thang, Macromolecules, 24, 3689 (1999).

10. E. Rizzardo, Y. K. Chong, R. A. Evans, G. Moad, and S. H. Thang, Macromol. Symp., 111, 1 (1996).

11. T. Sato, M. Seno, M. Kobayashi, T. Kohono, and H. Tanaka, Eur. Polym. J., 31, 29 (1995).

12. B. Yamada, S. Kobatake, and S. Aoki, Macromolecules, 26, 5099 (1993).

13. S. Kobatake and B. Yamada, J. Polym. Sci., Part A: Polym. Chem., 34, 95 (1996).

14. T. Harada, P. B. Zetterlund, and B. Yamada, J. Polym. Sci., 
Part A: Polym. Chem., in press.

15. T. Hirano and B. Yamada, Polymer, 44, 347 (2003).

16. S. Kobatake and B. Yamada, Macromol. Chem. Phys., 198, 2825 (1997)

17. B. Yamada, S. Kobatake, and S. Aoki, Polym. Bull., 31, 263 (1993).

18. K. Hatada, T. Kitayama, K. Ute, Y. Terawaki, and T. Yanagida, Macromolecules, 30, 754 (1997).

19. A. A. Gridnev and S. D. Ittel, Chem. Rev., 101, 3611 (2001).

20. J. P. A. Heuts, G. E. Roberts, and J. D. Biosutti, Aust. J. Chem., 55, 381 (2002).

21. B. Yamada, S. Tagashira, and S. Aoki, J. Polym. Sci., Part A: Polym. Chem., 32, 2745 (1994).

22. B. Yamada, F. Oku, and T. Harada, J. Polym. Sci., Part A: Polym. Chem., 41, 645 (2003).

23. J. Chiefari, J. Jeffery, R. T. A. Mayadunne, G. Moad, E. Rizzardo, and S. H. Thang, Macromolecules, 32, 7700 (1999).

24. J. Chiefari, J. Jeffeery, R. T. A. Maydunne, G. Moad, E. Rizzardo, and S. H. Thang, 'Preparation of Macromonomers via Chain Transfer with and without Added Chain Trans- fer Agent', in 'Controlled/Living Radical Polymerization. Progress in ATRP, NMP, and RAFT”, K. Matyjaszewski, Ed., ACS Symposium Series No. 768, American Chemical Society, Washington, D.C., 2000, p 21.

25. B. C. Gilbert, J. R. L. Smith, E. C. Milne, A. C. Whitwood, and P. Taylor, J. Chem. Soc. Perkin Trans. 2, 1759 (1994).

26. B. Yamada, M. Azukizawa, H. Yamazoe, D. J. T. Hill, and P. J. Pomery, Polymer, 41, 5611 (2000).

27. M. Azukizawa, B. Yamada, D. J. T. Hill, and P. J. Pomery, Macromol. Chem. Phys., 201, 774 (2000).

28. A. M. van Herk, Macromol. Rapid Commun., 22, 687 (2001).

29. D. J. Trumbo and R. A. Zander, J. Polym. Sci., Part A: Polym. Chem., 29, 1053 (1991).

30. B. A. Feit, Eur. Polym. J., 8, 321 (1972).

31. J. Fossey, D. Lefort, and J. Sorba, "Free Radicals in Organic Chemistry", John Wiley \& Sons, Ltd., Chichester, 1995, p 148.

32. K. Tanaka, B. Yamada, R. Willemse, and A. M. van Herk, Polym. J., 34, 692 (2002). 